\title{
Feminilizando sentidos sobre a natureza da ciência: Por mulheres e mulheres negras rappers
}

\begin{abstract}
Resumo: Base do processo do discurso, o "mecanismo de antecipação" constitui e formula significações do feminino-epistêmico de mulheres e de mulheres negras rappers, em cada Sul global. Esse mecanismo discursivo revela sentidos de mundo e tomadas de posição, ambos mediados, ideologicamente, em seus contextos socioculturais, como: escolas, universidades, instituições de pesquisa, coletivos feministas, ou o Movimento Hip-hop. Compondo aforismos sobre raça/cor, sexo/gênero e natureza/cultura, perfazem formações imaginárias, em colonialidade, das quais essas sujeitas buscam libertar-se. Assim, analisamos a feminilização do "processo do discurso" de mulheres, na América Latina e na África, por seus fazeres e dizeres, tanto na ciência quanto em rhythm and poetry (rap). Para tanto, utilizamos o referencial teórico-metodológico da Análise de Discurso, em seu viés franco-brasileiro, quanto aos processos de feminilização da "natureza da ciência" (NdC), pelo feminino-epistêmico, contidos em fazeres e em dizeres das referidas sujeitas. Os resultados desvelam importantes condições de significação, na produção de conhecimentos tecnocientíficos, por outra NdC. Esse instigante campo de análise mostrou-nos o funcionamento de sentidos sobre gênero-negritude, em contextos socioculturais de Sul global, e em outros, ora marginalizados (ruas, guetos, favelas, periferias), por formações discursivas que afetam a educação científica e tecnológica, em pluralidades femininas.
\end{abstract}

Palavras chave: mulher e educação; análise de discurso; construção de sentido.

\section{Sentidos inicias}

Por um gerúndio, formulamos, neste ensaio, como objetivo: analisar a feminilização do processo do discurso no meio sociocultural de mulheres e de mulheres negras rappers, na América Latina e na África, tanto em fazeres e dizeres na ciência como em rhythm and poetry (rap), para deflagrarmos possibilidades na educação científica e tecnológica, por outra "natureza da ciência" $(\mathrm{NdC})$. Esta encontra materialidade no fazer e no dizer das referidas sujeitas, compondo entes (i) materiais na práxis sociocultural: espaço-tempo de interpretação de múltiplos "racismos por omissão". (GONZALEZ, 2011)

Trabalhamos sobre o "pensamento-linguagem" (FREIRE, 1983) e a "memória discursiva/interdiscurso" (ORLANDI, 2015) de mulheres e mulheres negras rappers, no embate sociocultural contra-hegemônico, como: aparência assexuada vs. referencial teórico- prático, dominantemnte masculino; sujeitos em $3^{\mathrm{a}}$ pessoa do singular vs. autoria do branco,colonizador, eurocêntrico; a ciência popular vs.
Roberth De-Carvalho orientador.roberth@gmail.com Instituto Federal de Educação, Ciência e Tecnologia de Santa Catarina (IFSC) 
(1) Flow é a fluidez que a letra se combina com o ritmo, pela harmonização do ritmo da letra com a levada musical. Flow (ou levada) é a maneira como a rapper junta seus versos com a batida o método de institutos de ciência (o problema, o objeto, o objetivo, o conteúdo); sociedade científica vs. Sul global objetificado; subjetividade encoberta vs. agenciamento da objetividade; método quantitativo vs. qualificações sobre o real da história; mito/magia/ crença/transcendência vs. concretude do objeto; corpo/território vs. mente/razão.

Assim, tomamos o Movimento Hip-hop, pelo embate a projetos neoliberais, machistas, inferindo sobre: artes, mídias, textos/ discursos, redes sociotécnicas, histórias, literaturas, tecnologias, autorias, e que afeta o fazer-ser de professoras de Ciências, na Educação Básica. Estas, formadoras iniciais de "sentidos de mundo" (OYĚWÙMÍ, 2017), precisam atentar a vieses racista, capitalista, misógino, homo/transfóbico, eurocentrista, sexista, por uma leitura da "natureza da ciência" subjacente em materiais didáticos, em recursos de ensino, em suas didáticas, em seu planejamento/ avaliação. Principalmente, em bases, parâmetros e legislações que silenciam existências e pluralidades femininas.

A base linguística do rap (via flow flipado ${ }^{1}$ ), por essas mulheres negras, imprime sentidos sociológicos particulares de mundo. Em rede, geram um "corredor de saberes" (GASPARETTO, 2019) que constitui/formula uma natureza outra da ciência, por afetações do: social, experiencial, afetivo, fatídico, sinestésico. Na "[...] réplica/ resposta à situação vivida. [...] Constrói um flagrante." (ORLANDI, 2012, p. 199) Tecnologia de "[...] passagem do discurso a texto desemboca necessariamente na consideração do espaço-tempo (linearidade) e da dimensão (extensão de um corpo) da linguagem colocando em relação o comensurável com o incomensurável, o empírico com o simbólico e o político." (ORLANDI, 2012, p. 92)

Atravessadas pela "ideologia" (ORLANDI, 2015), de suas formações imaginárias, buscamos: como se conformam as condições estruturais constitutivas de corpos, mentes, gestos, reorientando dizeres e fazeres? Pois, a subjetividade se reitera colonialmente, e estabiliza-se em uma matriz de opressões, em forma de 'identidade', posta à disposição, como opção (AKOTIRENE, 2019.) Uma vez que "a ideologia não é ocultação mas função da relação necessária entre linguagem e mundo. Linguagem e mundo se refletem no sentido da refração, do efeito imaginário de um sobre o outro." (ORLANDI, 2015, p. 47)

Tomamos o gangsta rap, surgido na década de 1990, do qual emergem litígios sociológicos, quanto a: raça/cor, sexo/gênero, 
corpo/mente, divisão de classes/relações de poder, natureza/cultura, religião/misticismo. Por isso, situamos a importância da análise desse campo de tensões discursivas, no qual circulam sentidos, falhas semânticas, deslizamentos, deslocamentos, incertezas metafóricas. "[...] isto é o discurso, isto é o ritual da palavra." (ORLANDI, 2015, p. 10) Sendo a escola o espaço-tempo privilegiado, em disputa, ensejando o funcionamento de mediações socioculturais, ao mobilizar preceitos, premissas, regularidades e verdades científicas.

Assim, levantamos como problema: quais sentidos de feminilização para a constituição/formulação de uma natureza outra da ciência podem ser tomados, a partir de discursos de mulheres e mulheres negras rappers, pelo Sul global? Para respondê-lo, usamos o aporte teórico-metodológico da Análise de Discurso, sob a perspectiva franco-brasileira, a partir do filósofo francês Michel Pêcheux (1938-1983) e da linguista brasileira Eni P. Orlandi.

\section{Natureza da ciência em processo de feminilização}

Estudos de gênero, feminismos e políticas têm se deparado com entraves de organização, articulação e objetivos, quanto a investimentos, em contextos africanos. A pesquisadora nigeriana Amina Mama discute sobre isso no texto intitulado: "O que significa fazer pesquisa feminista em contextos africanos?", ' ao revelar que pesquisas sobre mulheres e sobre gênero atraem baixos investimentos, dado o entendimento errôneo de alguns gestores de que tais investimentos serviriam, apenas, para fomentar instituições carentes de recursos. (MAMA, 2011) Isso repercute sobre conteúdos sociais que operam no funcionamento de linguagens, em violência e silenciamento epistêmico, pela ciência do patriarcado.

Discursos femininos afrocentrados urgem na educação científica e tecnológica (ECT), para produzir sentidos de ensino (e de aprendizagem), por: percepções de vida, no fazer-ser da Biologia, em interlocução com o dizer-ser de ontologias feministas de negritudes; da Física ${ }^{3}$, pela identidade da mulher negra aferindo eventos sobre pontos materiais; ou, da Química, por diálogos em língua/ linguagem mística, alquímica (magias em: beberagens, garrafadas, lambedores, elixires, cataplasmas, chás/infusões).

Contexto em que situamos um exemplo de fazer-ser, pelo movimento estudantil brasileiro \#Ocupatudo, ocorrido em 2015, no qual meninas-mulheres lutaram por direitos estudantis, ante
(2) do original: What does it mean to do feminist research in African contexts?

(3) Agrello e Garg (2009) constatam, a partir do ensino de Física, a força do patriarcado nas ciências, ao lidarem com desenhos de meninas, para remeterem sentidos sobre cientistas. É dominante a produção de figuras masculinas. 
(4) Contraditoriamente, Geraldo Alckmin fora eleito com $57 \%$ de votos válidos, no pleito de 2014, pelo Partido da Social Democracia Brasileira (PSDB), que, politicamente, é considerado como partido de centro, representando o "'mito da neutralidade" político-partidária latino-americana. A época, seu Secretário de Educação, Herman Voorwald (gestão: 2011-2015), de ascendência holandesa, reforçava um staff de homens, brancos e elitistas.

(5) No Brasil, o ministro da economia, Paulo Guedes, em fevevereiro de 2020 , relativizou e ironizou a condição dessas mulheres, de maioria negra e favelizada, ao dizer: "Empregada doméstica indo para Disney, uma festa danada..." Desculpou-se com: "Mãe do meu pai foi doméstica." Porém, o fez reiterando a superestrutura do patriarcado, pelo efeito ético-normativo subsumido no masculino (pai), dissipando a natureza do feminino- epistêmico (mãe, doméstica), na significação discursiva.

(6) Ressaltamos, aqui, a metodologia de seminários e mesas-redondas no decurso dessa disciplina, em protagonismos de Outras mulheres, negras, cis e trans, que constituíram/formularam o ente corpo-mente- território epistêmico na composição de uma "'natureza" outra da ciência. uma suposta 'reorganização administrativa e pedagógica' imposta às escolas públicas do Estado de São Paulo ${ }^{4}$. Esse evento gerou o documentário brasileiro: Lute como uma menina! (LUTE..., 2016), com articulação política de variadas origens: negra/mestiça, favelizada, filhas de domésticas/diaristas ${ }^{5}$, serventes, merendeiras, professoras, (des)(sub)empregadas. Todas autoras naquele 'espaço de dizer' (GIRALDI, 2010) (escola, sala de aula, movimentos sociais, poetry slam, música, dança, grafite, rap), do qual emergem leituras e escritas, constituindo/formulando cidadanias justas, plurais e autorais.

Em outro nível acadêmico, situamos a categoria gênero-negritude, que renega "[...] aforismos matemáticos hierarquizantes ou comparativos [...]" (AKOTIRENE, 2019, p. 43), constituindo novíssimas tecnologias de linguagem que ressaltam estudos sobre organizações e 'feminismos africanoS' sul-sul, pela comunicadora social Vera Fátima Gasparetto; pesquisas sobre histórias de mulheres, gênero, emoções e resistências no cone Sul, pela historiadora Cristina Scheibe Wolff; pesquisas literárias feministas pós-coloniais/ decoloniais, transnacionais e intersexuais, pela linguista Simone Pereira Schmidt.

As referidas pesquisadoras ministraram, em 2019, em 60 horas-aula, a disciplina: Feminismos ao Sul: África e América Latina, ofertada no Programa de Pós-Graduação Interdisciplinar em Ciências Humanas (PPGICH), pela Universidade Federal de Santa Catarina. Esse espaço de interpretação deflagrou uma perspectiva feminino-epistêmica que se revelou na "[...] construção de diálogos políticos, afetivos e estéticos no âmbito Sul-Sul." (WOLFF; SCHMIDT; GASPARETTO, 2019, p. 1), por uma forma-conteúdo acadêmicoinvestigativa de mulheres, em sua maioria negras ${ }^{6}$, em diáspora. O que nos fez atentar para o fato de que: "O feminismo descolonial trata-se de uma intervenção teórica sobre a ideia de gênero e sexo no esquema de Quijano, amparando-se e animando-se empiricamente nos diferentes feminismos americanos - latino, negro, chicano, 'de cor', indígena e comunitário." (BALLESTRIN, 2017, p. 1045).

Raça e sociedade como variáveis limítrofes, que inferem o fazer acadêmico, e que se contrapõem à situação da população negra, da qual emergiram projetos bastante radicais, pela formulação de "textos quentes" e "falas duras" (RATTS, 2006), ambientando confrontos epistemológicos em um contra-discurso de intelectuais brancas. 
Com isso, passaremos a descrever a base teórico-metodológica e os dispositivos de análise da pesquisa.

\section{Discurso e natureza da ciência por mulheres negras rappers}

Nesta seção, apresentamos o aporte teórico-metodológico com o qual operacionalizamos nossa pesquisa, bem como o corpus de análise (subseção 3.1). Em seguida, procedemos à análise discursiva do que defendemos, anteriormente, por uma 'natureza da ciência em feminilização' (subseção 3.2).

Aporte teórico do discurso

A Análise de Discurso, em Orlandi (1996; 2015; 2017) e Pêcheux (2015), tem a premissa da não transparência da linguagem, bem como de sua afetação ideológica. E, isso se perfaz em polissemias e paráfrases, pelo imaginário de sujeitas, que formulam e constituem textos e discursos.

Em gestos de interpretação, "[...] a Análise de Discurso, com seus dispositivos (teórico e analítico, E. Orlandi, 1996), nos permite interrogar a interpretação, compreender como um texto, seja de que natureza material for, produz sentidos." (ORLANDI, 2017, p. 318). Assim, interrogando a interpretação, confrontamos "[...] os efeitos ideológicos que atravessam toda discursividade face à constituição dos sujeitos e dos sentidos." (ORLANDI, 2017, p. 318), ante os "mecanismos de antecipação" de mulheres negras rappers.

É importante situar nosso lugar/posição, predicado do sujeito analista, sendo: homem, negro, da periferia, latino-americano, e que se afeta por movimentos socioculturais que traduzem, histórico-politicamente, fazeres e dizeres artísticos e tecnocientíficos, orientados para a libertação social, possibilitando dimensões para um referencial de pluricidadanias. Sob o efeito-leitor (de nossa formação imaginária), em colonialidade patriarcal, tomamos o cuidado de suprimir tendências androcêntricas e linearidades científicas, feminilizando nossos gestos de interpretação

Dessa forma, esse projeto foi construído entre os anos/semestres de 2019/2 e 2020/1, na disciplina "Feminismos ao Sul: África e América Latina", ofertada no PPGICH/UFSC (em 2019/2). Do aporte teórico-metodológico da referida disciplina, o mesmo encontrou 
um espaço-tempo profícuo na função autora de mulheres negras rappers (ver Quadro 1, que segue), nosso "dispositivo teórico".

Quadro 1 - Dispositivos teóricos analisados

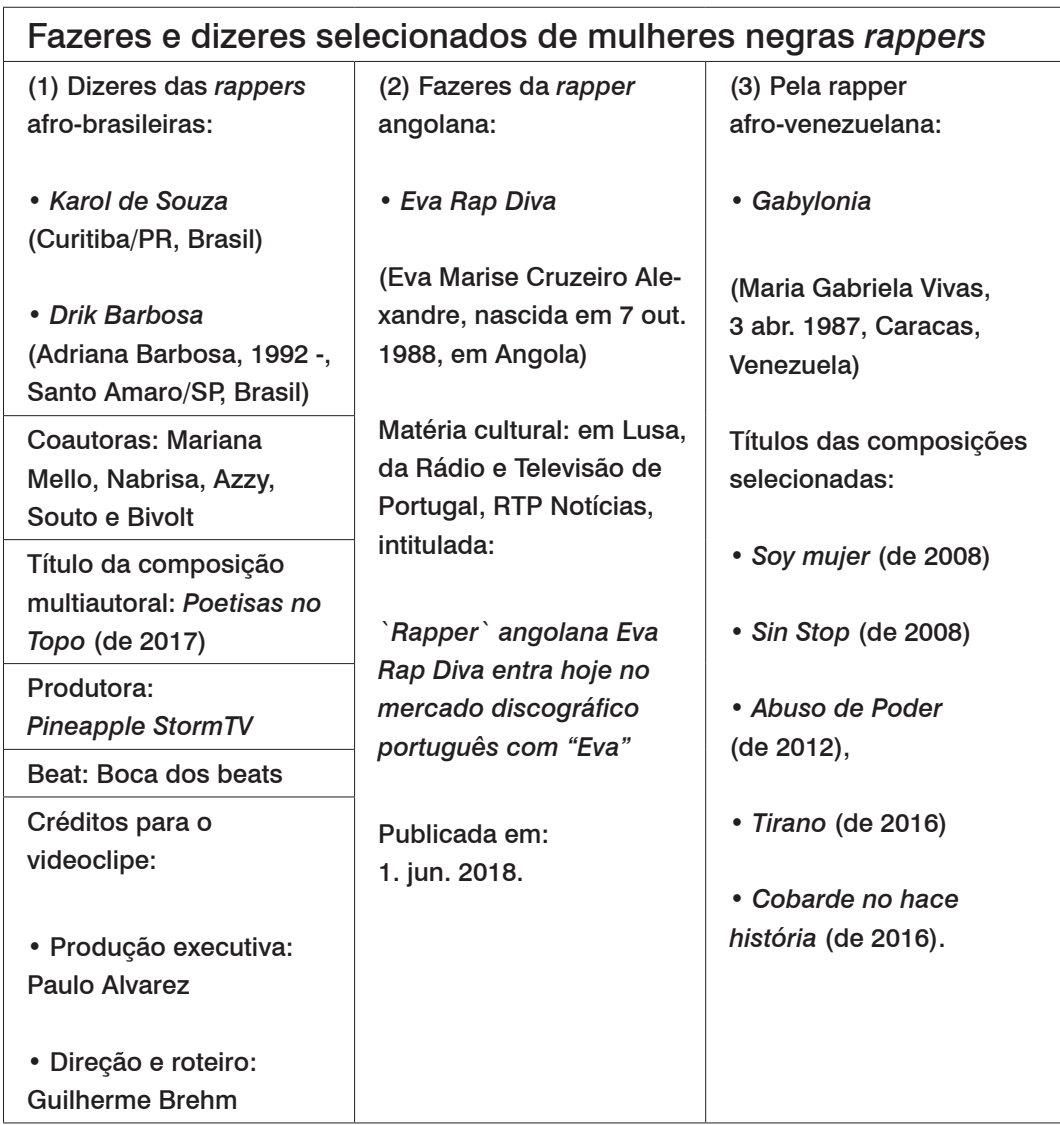

Fonte: elaborado pelo autor.

Base de constituição/formulação do 'processo do discurso' (PÊCHEUX, 2015), os "mecanismos de antecipação" no rap de mu1heres negras enunciam ontologias e epistemologias dominantes, às quais se afiliam, em cada Sul global. Dessa forma, ao assimilarmos tal mecanismo, centramos no trabalho "[...] de experimentar, ou melhor, de colocar-s no lugar em que seu interlocutor 'ouve' suas palavras. [...] antecipa-se assim a seu interlocutor quanto ao sentido que suas palavras produzem. Esse mecanismo regula a argumentação [...]." (ORLANDI, 2015, p. 39) Pois, ao argumentarem sobre 'sentidos de mundo' (OYĚWÙMÍ, 2017) que as afetam geopoliticamente, deflagram sua tomada de posição discursiva, quanto 
a corpos-mentes-territórios, em regularidade simbólico-histórica: de saberes-sentidos, em gênero-negritude.

Assim, dos fragmentos discursivos, que selecionamos para a pesquisa, marcamos: (a) os saberes-sentidos de ancestralidade, sendo: mito, magia, crendice, mãe-natureza, mãe-do- corpo, corpo-aberto, reza, benzimento, simpatia, danças rituais, amuletos. Estes, tomados como intangíveis/imateriais, a-científicos, não objetivos, não empiristas, no seio de difusas relações capitalistas em disputa, se pensarmos em projetos de ciência e tecnologia (CET) pelo Sul global; (b) os saberes-sentidos institucionais e tecnocientíficos, como: diversidade epistêmica; função autora; tecnologia; infraestrutura gerencial e formação do Estado; e, escola. Em ambos os casos, situamos semânticas de natureza afrocêntrica, "amefricanizadas" (GONZALEZ, 2011), silenciadas por situações-problema, deslocando forma-conteúdo autóctone, sob "colonialidade". Isso, para desvelarmos como opera o poder colonial, institutivo da $\mathrm{NdC}$, e que racializa (não)problemas em hierarquia no trabalho da tecnociência. Ao par, revelamos possibilidades entre polissemias e paráfrases, um jogo que "[...] atesta o confronto entre o simbólico e o político. Todo dizer é ideologicamente marcado. É na língua que a ideologia se materializa. Nas palavras dos sujeitos." (ORLANDI, 2015, p. 38)

Como critério de inclusão, buscamos, no fazer-ser das sujeitas de pesquisa, duas camadas de interseccionalidade: ( $\left.1^{\text {a }}\right)$ Pela compreensão da condição de mulher, negra ( preta $\left.^{7}\right)$ e rapper - Camada primária de interseccionalidade - corroborada em dizeres e fazeres, os quais validam-se, sobremaneira, pela grande circulação de seus trabalhos artísticos (rap), entre jovens em identificação, e em idade escolar, nos países que residem, sendo: Karol de Souza e Drika Barbosa, no Brasil; Babylonia, na Venezuela; e, Eva Rap Diva, em Angola. (2 ${ }^{\mathrm{a}}$ ) A partir de audições e/ou leituras on-line dessas composições, marcarmos sua "memória discursiva/interdiscurso", ou seja, "[...] dizeres que afetam o modo como o sujeito significa em uma situação discursiva dada.", como também "[...] sentidos já ditos por alguém, em algum lugar, em outros momentos, mesmo muito distantes, têm um efeito sobre [...]" (ORLANDI, 2015, p. 31) as categorias: corpo, periferia, gênero, feminismo e racismo - Camada secundária de interseccionalidade.
(7) Marcador definido pelo critério de heteroidentificação, adotado pelo Instituto Brasileiro de Geografia e Estatística (IBGE) em que: "A identificação de determinadas feições e o seu revestimento de um significado 'racial' exige um contexto ideológico específico que thes outorgue sentido." (IBGE, 2013, p. 22) $E$, no caso particular, atribuímos à fenotipia do conjunto harmônico dessas mulheres. 
(8) São coautoras: Mariana Mello, Nabrisa, Azzy, Souto e Bivolt. O clipe contabiliza 15.339.649 de visualizações, no canal da referida produtora PineappleStormTV (com 9,5 milhões de inscritas/os), na plataforma YouTube. Disponível em: https://www.youtube.com/ watch? $v=0 Z Y$ IIPPLfjY\&amp;t=264s. Acesso em: 23 nov. 2021

\section{Natureza da ciência por gênero-negritude}

O beat Poetisas no topo, lançado em 30 de dezembro de 2017, produzido pela Pineapple StormTV, é um rap multiautoral ${ }^{8}$, do qual destacamos os dizeres de duas de suas autoras, Karol de Souza e Drik Barbosa, que seguem:

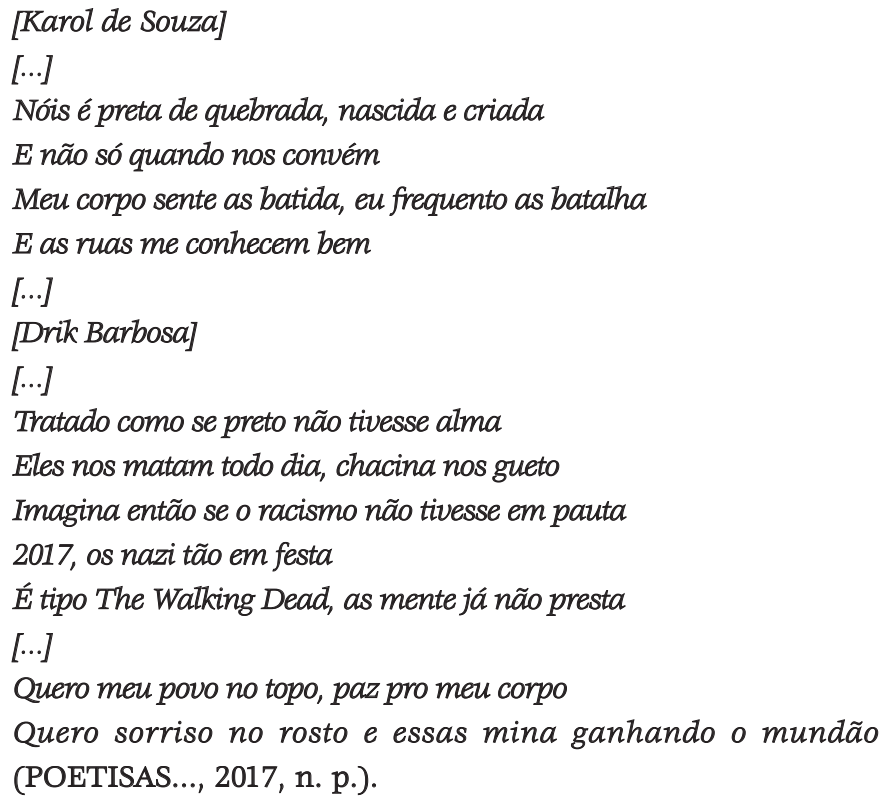

Nas 'condições de produção' desse discurso, o marcador étnico-racial se adensa, em: preta, corpo, alma, quebrada/gueto, racismo, mente. Militam, sociologicamente, pela $\mathrm{NdC}$, ambiente funcional em que se concretizam saberes-sentidos sobre conhecimentos científicos, por aprendizagens na educação formal, informal/ incidental ou não-formal. Assim, encontramos a dupla camada de interseccionalidade (preta da quebrada; meu corpo sente; mina ganhando a multidão; racismo em pauta), por saberes-sentidos institucionais (ruas me conhecem bem; chacina nos gueto) e tecnocientíficos (É tipo The Walking Dead, as mente já não presta; paz pro meu corpo). O que nos revela "[...] os tênues limites e relações instáveis que marcam, nas fronteiras da linguagem, e da vida, na relação indivíduo/sociedade, os sentidos de sua existência." (ORLANDI, 2017, p. 233)

A mulher negra latino-americana, assim como em África, experimenta "Com os anos 90, e com a abertura à democracia e ao multipartidarismo [...] outras narrativas, outros momentos de 
questionamento, [...] outros espaços de violência que estavam até então ocultos." (MENESES, 2012, p. 97). Espaços surgidos em distintos contextos do Sul global, desafiando pertenças ancestrais. "São, como Ungulani ba ka Khosa lhes chama 'orgias de loucos'. Os americanos fazem no Iraque; o exército português fez o mesmo em Moçambique, em Angola e na Guiné. O exército sul-africano também, assim como os grupos armados Hutus no Ruanda." (MENESES, 2012, p. 102)

Nessas narrativas, situa-se a referencialidade corpo-mente-território - hibridizada no pensamento-linguagem de mulheres, negras, cosmopolitizadas em ambientes de repressão -, no fazer-ser e no dizer que flutuam, como currículo, como disciplina de uma instituição, que, embora não legitimada pelas facetas do projeto neoliberal, se perfaz por sentidos e sujeitas, em associação ideopolítica à sua função autora. (GIRALDI, 2010) "Dizer isto, no entanto, não é novidade para muitas teóricas feministas como Donna Haraway, Susan Hekman, Stacy Alaimo, Karen Barad e outras que, atuando nas ciências ditas exatas, escrevem sobre o (re)retorno da matéria na teoria social (vitalismo crítico) [...]" (COSTA; FUNCK, 2017, p. 904). Isto, para pensarmos como espécie (species-thinking), pois "emaranhadas com outras espécies/materialidades (como nos lembra Haraway, somos multiespécies)." (COSTA; FUNCK, 2017, p. 904)

À revelia de suas geografias, sistematizam sentidos de ausências, pelo efeito de uma neutralidade, que o discurso científico não ressaltaria sobre essas materialidades ontológicas, ao dizerem de explorações de corpos, de tentativas de destituição de transcendências - saberes-sentidos de ancestralidade. Assim como de recorrentes mortes/violências: biológicas, físicas, químicas; por silenciamento; por apagamento; por esquecimento (RATTS, 2006); por ganâncias de empresas políticas, elitistas e patriarcais da branquitude. Pelas ruas, laboratórios do gueto, da quebrada, experienciam um espaço-tempo de interpretação, demonstrando, empiricamente, a exogenia do objeto de estudo: de dentro de si, para o mundo; contrariando os mecanismos endógenos de produção das ciências da natureza. Essas, convencionalmente, formam sujeitas para extraírem amostras do objeto de estudo, por ambientes não domésticos, ao confiná-lo, observá-lo metodicamente, enquadrá-lo teoricamente sob uma referencialidade, visto sob regularidades fenomênicas que não variam, aquém do espaço-tempo de leis, axiomas, postulados, prescrições teóricas - saberes-sentidos tecnocientíficos. "Isso supõe que o 
(9) do original: "Bissau-Guinean raperu (rappers) often live in fear and face threats, censorship, and possible military beatings." (GOLDISMITH; FONSECA, 2018, p. 303) sujeito deixe de ser considerado o eu-consciência mestre do sentido e seja reconhecido como assujeitado ao discurso [...] O efeito-sujeito aparece então como resultado do processo de assujeitamento e, em particular, do assujeitamento discursivo." (PÊCHEUX, 2015, p. 156, grifos do autor)

Essa funcionalidade sociopolítica reclama cidadanias plurais e democracias participativas, as quais se interceptam à Terceira onda do feminismo (iniciado na década de 1990), pelo chamado gangsta rap. Este, carregado de misoginia, cuja raiz de opressão política neoliberal e centralidade do poder masculino heteronormativizado, relega-as à margem, deslocando-se do epicêntro de seus opressores. (GOLDSMITH; FONSECA, 2018) O que as leva a desviarem-se, por uma "[...] experiência vibrante de construção das novas identidades negras nos movimentos culturais e políticos da negritude, da black renaissance norte- americana, seguidos pelos movimentos de libertação na África." (SCHMIDT, 2019, p. 6, grifo da autora) Emergindo novas identidades socioculturais e políticas, em estado de:

[...] uma intelligentsia negra, o fantasma vivo do escravizado para além do Atlântico, sua presença no começo da Modernidade como signo de insurreição que, em sua radicalização, não deixa de lembrar que, no que concerne a liberdade, só existe ter direito. E que, enquanto isso não tiver sido estendido a todos, podemos falar de qualquer coisa, menos de democracia. (MBEMBE, 2019, p. 47 , grifos do autor)

Pela democracia, em África, destacamos a situação do rap engajado, em Guiné-Bissau, disseminado por áreas urbanas e rurais, contra o movimento político militarizado, no lado ocidental daquela região, ao denunciar: violência, corrupção, disparidade econômica, injustiças sociais, uso generalizado de drogas e tráfico humano. Textualizado com maior frequência em língua creole, (falada por $70 \%$ da população), ocasionalmente, ocorrem letras em língua portuguesa - língua colonial; uma vez que essas letras sofrem retaliação da política militarizada, naquele país. "Os raperu (rappers) guineenses vivem, a todo tempo, com medo, pois enfrentam ameaças, censuras e espancamentos da polícia." (GOLDSMITH; FONSECA, 2018, p. 303; tradução nossa) ${ }^{9}$ Nessa conjuntura de lutas pela democracia, o país - juntamente com Angola e Guiné Equatorial (todos lusófonos) - ainda sofre com o 
decréscimo no índice de desenvolvimento humano (IDH). E, em sentido contrário, o aumento de casos de preconceito de gênero ${ }^{10}$. Tal preconceito de gênero estimula uma série de feminicídios ${ }^{11}$. Riscos em que, Eva Rap Diva, de Angola, reflete sobre seu fazer-ser, como artista, ao antecipar-nos:

Se fosse homem acredito que seria mais fácil, mas não seria tão gratificante, talvez, porque tudo o que eu conquisto acaba por ser uma conquista para todas nós, mais uma pedrinha colocada no monte que temos que fazer para chegar até ao sol, no que toca ao 'rap' feito por mulheres. [...] Se falarmos em 'rap' no feminino para podermos dar mais destaque às mulheres pode ser feito, se não o 'rap' é 'rap' e não tem género. [...] para que essa minoria possa estar em pé de igualdade com o outro género, o que não acontece nos dias de hoje. (EVA RAP DIVA apud LUSA, 2018).

Eis a ciência da minoria, que confronta o sistema ético-normativo das Ciências da Natureza hegemônicas. Sistema sob bases teóricas/retóricas, assentadas sob condicionantes de taxonomias, de nomenclatura, de raça. Leis de uma natureza capital que interditam outras epistemes, as mesmas que outrora o patriarcado não permitiu ser inteligível, assimilável e factível. "O que está posto em causa, nessas 'novas' leituras, são as evidências do estritamente bio-social, dando-se, ao contrário, relevância, aos mecanismos de linguagem, ao simbólico, e ao histórico social." (ORLANDI, 2012, p. 60) - forja-se a dupla camada de interseccionalidade que buscamos (conquista para todas nós; não tem género), por ambas as tipologias de saberes-sentidos: institucionais (minoria; pé de igualdade) e tecnocientíficos (rap feito por mulheres; outro género). Assim, a rapper ajusta:

[...] seu dizer a seus objetivos políticos, trabalhando esse jogo de imagens. [...] O imaginário faz necessariamente parte do funcionamento da linguagem. [...] A imagem que temos de um professor, por exemplo, não cai do céu. Ela se constitui nesse confronto do simbólico com o político, em processos que ligam discursos e instituições. (ORLANDI, 2015, p. 42)

Esse é o mecanismo de antecipação constituindo "[...] novas tecnologias de linguagem como desenvolvimento no domínio da tecnologia da escrita [...]" (ORLANDI, 2012, p. 149), ao deflagrar outras tecnologias do dizer, na formação imaginária. Nesse caso,
(10) Definido pelo Índice de Normas Sociais, o mesmo fora incluído pela primeira vez no

Relatório de Desenvolvimento Humano (RDH-2019). Ver: https://www.dw.com/pt-002/ angola-e-guin\%C3\%A9-bissaupioram-no-\%C3\%ADndice-de desenvolvimento/a-51600978

(11) Marcadamente, pelas Américas Central e Latina, a cada 100 mil hab., pesquisa Organização das Nações Unidas (ONU) demonstra o efeito da violência (em ordem decrescente): El Salvador (8.9), Colômbia (6.3), Guatemala (6.2), Rússia (5.3), Brasil (4.8), México (4.4), Moldávia (3.3), Suriname (3.2), Letônia (3.1) e Porto Rico (2.9) (FERRAZ, 2017). 
(12) Masculino-epistêmico constitutivo de múltiplos domínios socioculturais, como: llinguagem,

deidade, família, status quo economia, militarização, tecnologia/ tecnocracia, ética, estética, institucionalização, direito/justiça, diplomacia, esporte etc.

(13) Letra em: https://www.letras. mus.br/gabylonia/soy-mujer/. Acesso em: 8 fev. 2020.

(14) Letra em: https://www.letras. mus.br/gabylonia/abuso-de-poder/. Acesso em: 8 fev. 2020.

(15) Letra em: https.://www.letras. mus.br/gabylonia/sin-stop/. Acesso em: 8 fev. 2020.

(16) Letra em: https:// lyricstranslate.com/pt-br/gabyloniatirano-lyrics.html. Acesso em: 9 fev. 2020

(17) Letra em: https://www. paroles-musique.com/eng/ Gabylonia-Cobarde No Hace Historia-lyrics,p056000870. Ácesso em: 10 fev. 2020. dizeres em fuga do espaço-tempo faloceno,$^{12}$ por uma comunidade flutuante de mulheres, em quilombo ou mocambo de ideias. E, assim, constituem-se resistências feminino-epistêmicas, sendo que:

Nas Américas se desenvolveram pequenas, médias, grandes, improvisadas, solidificadas, temporárias ou permanentes comunidades de fugitivos que receberam diversos nomes, como cumbes na Venezuela ou palenques na Colômbia. Na Jamaica, no restante do Caribe inglês e no sul dos Estados Unidos foram denominados maroons. Na Guiana holandesa - depois Suriname - ficaram também conhecidos como bush negroes. No Caribe francês o fenômeno era conhecido como maronage; enquanto em partes do Caribe espanhol - principalmente Cuba e Porto Rico - se chamava cimaronaje. (GOMES, 2015, p. 9-10, grifos do autor).

A rapper afro-venezuelana Gabylonia formula-se, ao dizer: (a) Da diversidade epistêmica, nos versos de Soy mujer ${ }^{13}$, de 2008: Hay diferentes estilos mujeres de pico y pala / Asi mismo la intercalo y en tu cerebro se instala; (b) Da função autora, nos versos de Abuso de poder ${ }^{14}$, de 2012: Vine a decirte de parte del pueblo raperos sin peros seguimos enteros / Vinimos de cero guerreros sinceros voceros de acero; (c) Da tecnologia do próprio dizer, nos versos de Sin stop ${ }^{15}$, de 2008: Sin stop porque puedo decirte cantando lo que positivo escribo / Para que muestres tu alma y con calma sigas manteniéndote vivo; (d) Da desconstrução institucional, gerencial e estética do Estado, nos versos de: Tirano ${ }^{16}$, de 2016: Inversionista, no insista en cambiar mi punto de vista, / ya tengo una lista de oportunistas con los artistas, / no voy a vestirme así, como usted quiere que me vista / por salir en las revistas, yo no soy materialista; ou ainda, (e) Da necessidade de outra escola, de outra educação, na estrofe de Cobarde no hace historia ${ }^{17}$, de 2016: Los militares norteamericanos siguen violando a mujeres africanas, / Mis hermanos siguen protestando por el bloqueo que continua en la habana, / En las fronteras siguen matando a los colombianos y a mi gente mexicana, / En la republica bolivariana siguen y siguen muertes inhumanas... CHILE! / Usan su voz como fusiles, batallando en marchas estudiantiles, / Niños son útiles pa llevar de diles, to hacen para que no los aniquilen. Transnacionaliza o problema, o objeto, o objetivo, reformulando a função sociocultural do fazer científico, pelo gênero, pelo feminismo que lhe afeta, atenta aos impedimentos racistas. É um jogo discursivo entre "relações de força"e "relações de poder" (ORLANDI, 2015), organizado por uma 
antevisão de posicionalidade (simbólica e política), que entende estar ocupando seus interlocutores.

Isso nos revela que: "O dizer não é propriedade particular. As palavras não são só nossas. Elas significam pela história e pela língua. O que é dito em outro lugar também significa nas 'nossas' palavras. O sujeito diz, pensa que sabe o que diz, mas não tem acesso ou controle sobre o modo pelo qual os sentidos se constituem nele." (ORLANDI, 2015, p. 32)

Nessa interseccionalidade, o grupo feminista de Valparaíso, no Chile, LASTESIS - Colectivo Interdisciplinario de Mujeres, ${ }^{18} 1$ lançou em 18 nov. 2019, por ocasião da Segunda Comisaría de Carabineros de Chile, o hino: Un violador en tu caminho.$^{19}$ Contando com a presença, aproximada, de 2.000 mulheres (em 25 nov. 2019), o hino ecoou pelo mundo, como parte da programação do Dia Internacional da Eliminação da Violência contra Mutheres, instituído pela Res. n. 54/134. (UNITED NATIONS, 2000) Nos versos: El violador eras tú. / El violador eres tú. / Son los pacos, / los jueces, / el Estado, / el presidente [...], aquelas mulheres, vendadas, mostraram ao mundo o estado atual da NdC que as tem objetificado, pelas vias de poder do patriarcado.

Em suspenso, ao feminilizarmos a NdC, instiga-nos: "Que sentidos vão-se constituindo na determinação histórica dos processos de significação (estigmatização/violência/resistência), a vida sendo cada dia mais inviável?". (ORLANDI, 2017, p. 232)

\section{Sentidos finais}

O rap des-transforma - nos diz Orlandi. Espaço-tempo de significações que analisamos, pela via de duas camadas de interseccionalidade, sendo: pela notoriedade de mulheres, negras e rappers no Sul global, constitutiva das categorias gênero, feminismo e racismo. Isso, para deflagrarmos os efeitos de sentido em projetos onto-epistêmicos, que as excluem. E, pelos quais buscamos significações de um flagrante discursivo: o feminino- epistêmico.

Das materialidades textual e discursiva, ressaltamos pautas de mulheres e de mulheres negras, promovendo denúncias sobre o jogo de intenções, em suas polissemias e paráfrases. Para tanto, marcamos, a partir dos dispositivos teóricos que selecionamos (no cerne do rap), o efeito-leitor sobre a NdC, constituído de saberes-sentidos institucionais e tecnocientíficos, como importantes
(18) Ver: https://www.instagram com/lastesis/. Acesso em: 1 maio 2021.

(19) Hino disponível em: https:// elpais.com/sociedad/2019/12/07/ actualidad/1575750878 441385 html. Acesso em: 10 fev. 2020. 
variáveis de análise. Saberes-sentidos que, dentro de camadas de interseccionalidade, revelaram o ser-mulher, no embate à ideologia de ausências, afirmando sua posição em corpo-mente-território.

Inferências sobre uma natureza hegemônica da ciência, contestada pela via da descolonização, em silêncios, equívocos, esquecimentos, deslizamentos (elementos da análise de discurso que ora trabalhamos). E, expressadas em formas-conteúdos históricos de ciência e tecnologia, que objetificam e relativizam a existência dessas mulheres, seu protagonismo autoral, seus problemas tecnocientíficos, por suas políticas de inclusão. E, pelas estatísticas, marcadamente, de mulheres negras. Entendemos, assim, o feminino-epistêmico, em litígio, na escola básica.

A pesquisa revelou facetas do trabalho institucional da ciência, e da tecnologia, segregado de interlocuções socioculturais, ao verticalizar a lógica de validação (pelo: problema, objeto, objetivo, conteúdo, método) de efeitos-autores, que ensinamos e que aprendemos na escola. Isso urge ser revisado em materiais de ensino, em disciplinas, em laboratórios, em currículos, quanto à constituição/formulação do atual fazer científico, que não responde ao cerne de problemas Sul globais. Da especificidade contida em cada pensamento-linguagem da pesquisa, são reclamadas interseccionalidades feminino-epistêmicas, existências plurais, pacifistas, democraticamente participativas, de amor e equidade, para justiças social e cognitiva. Espaço-tempo que deve ser privilegiado na educação em ciências.

Pelas escolas brasileiras, do \#Ocupatudo; pelas universidades, curricularizando Feminismos ao Sul; pelo recém-adotado hino feminista, traduzido da língua espanhola (do Chile), alcançando megalópoles, como: Paris, Londres, Barcelona, Nova York, Cidade do México, Istambul, Madri, Berlim e Bogotá; tudo se interseccionou no hip-hop do Sul global, feminilizando a NdC, em sentidos de alteridade, de gênero-negritude, para outros fazeres e dizeres tecnocientíficos.

\section{Feminizing Meanings About The Nature Of Science: By Women And Rapper Black Women}

\footnotetext{
Abstract: Process of discourse support, the "antecipation mechanism" constitute and formulate significations of a feminine-epistemic of women and rapper black women of each global South. This discoursive mecanism reveals world meanings to a positional act that is ideologically mediated in its sociocultural contexts, like: schools, universities, reseach institutes, feminist
} 
collectives, or the Hip hop Movement. Composing aforisms about race/color, sex/gender and nature/culture, perform imaginary formations on coloniality about which these subject seek to break free. In that sense, we analize the feminization of women's "discourse process" in Latin America and in Africa, by their makings and sayings, in the science as well as in rhythm and poetry (rap). Therefore, we utilize the theoretical-methodological framework of the Analysis of Discourse, in its Franco-Brazilian bias, about the feminization processes of the "nature of science"' (NoS), by the feminine-epistemic, contained in makings and sayings of these subject. The results reveal important conditions of meaning in the production of technoscientific knowledges, by another NoS. That exciting field of analysis showed us the operation of meanings about gender-blackness within sociocultural contexts and marginalized (streets, ghettos, slums, peripheries), by discursive formations that affect scientific and technological education, in feminine pluralities.

keywords: woman and education; analysis of discourse; making of meanings.

\section{Sentidos Feminilizadores Sobre La Naturaleza De La Ciencia: Para Mujeres Negras Y Mujeres Rappers}

Resumen: Base de proceso del discurso, el "mecanismo de anticipación" constituye y formula sentidos femenino-epistémicos de mujeres y de mujeres negras rappers en cada Sur global. Este mecanismo revela sentidos de mundo y toma de posiciones mediadas ideológicamente en los contextos socioculturales, como: escuelas, universidades, instituciones de investigación, colectivos feministas, o el Movimiento Hiphop. Compondo aforismos de la raza/color, sexo/género y naturaleza/cultura traducen formaciones de lo imaginario en colonialidad, de las cuales esas sujetas buscan libertarse. Entonces, analizamos la feminización do "proceso del discurso" de mujeres, en Latinoamérica y África, por sus haceres y decires, tanto en ciencia como en rhythm and poetry (rap). Para eso usamos el marco teórico-metodológico del Análisis del Discurso, en su sesgo franco-brasileño, cuanto a los procesos de feminización de la "naturaleza de la ciencia" (NdlC), por lo femenino-epistémico, en haceres y decires de las sujetas. Los resultados revelan importantes condiciones de significación en la producción de conocimientos tecnocientíficos, por otra NdlC. Este sugerente campo de análisis nos mostró el funcionamento de los sentidos sobre género-negritud en los contextos socioculturales de Sur global y marginados (calles, guetos, tugurios, periferias), por formaciones discursivas que inciden en la educación científica y tecnológica, en pluralidades femeninas.

Palabras clave: mujer y educación; análisis del discurso; producción de sentidos.

\section{Referências}

AGRELLO, D. A.; GARG, R. Mulheres na física: poder e preconceito nos países em desenvolvimento. Revista Brasileira de Ensino de Física, São Paulo, v. 31, n. 1, p. 1305- 1/1035-6. 2009. Disponível em: www.sbfisica. org.br. Acesso em: 2 fev. 2020.

AKOTIRENE, C. O que é interseccionalidade. São Paulo: Sueli Carneiro, 2019. (Coleção Feminismos Plurais). 
BALLESTRIN, L. M. A. Feminismos subalternos. Revista Estudos Feministas, Florianópolis, v. 25, n. 3, dez. 2017. p. 1035-1054.

Disponível em: http://www.scielo.br/scielo.php?script = sci_ arttextEamp;pid = S0104- 026X2017000301035\&amp;lng = en\&amp;nrm = iso . Acesso em: 5 jan. 2020 .

COSTA, C. L.; FUNCK, S. B. O antropoceno, o pós-humano e o novo materialismo: intervenções feministas. Revista Estudos Feministas, Florianópolis, v. 25, n. 2, p. 903-908, ago. 2017. Disponível em: http:// dx.doi.org/10.1590/1806-9584.2017v25n2p903 . Acesso em: 20 nov. 2019.

FERRAZ, N. Feminicídio: 10 países com maior taxa de violência contra a mulher. Blastingnews, [Lugano], 28 jan. 2017. Disponível em: https:// br.blastingnews.com/sociedade-opiniao/2017/01/feminicidio-10-paisescom-maior-taxa-de-violencia-contra-a-mulher-001427789.html . Acesso em: 22 jan. 2020.

FREIRE, P. Extensão ou comunicação? Tradução: Rosisca Darcy de Oliveira. 7. ed. Rio de Janeiro: Paz e Terra, 1983. (O Mundo, Hoje, v. 24)

GASPARETTO, V. F. Corredor de saberes: Vavasati Vatinhenha (mulheres heroínas) e redes de mulheres e feministas em Moçambique. 2019.

Tese (Doutorado em Ciências Humanas) - Programa de Pós-Graduação Interdisciplinar em Ciências Humanas, Universidade Federal de Santa Catarina, Florianópolis, 2019.

GIRALDI, P. M. Leitura e escrita no ensino de ciências: espaços para produção de autoria. 2010. Tese (Doutorado em Educação Científica e Tecnológica) - Universidade Federal de Santa Catarina, Florianópolis, 2010.

GOLDSMITH, M. U. D.; FONSECA, A. J. Hip Hop around the world: an encyclopedia. Westport: Greenwood Publishing Group, Inc., 2018. v. 2.

GOMES, F. S. Mocambos e quilombos: uma história do campesinato negro no Brasil. São Paulo: Claro Enigma, 2015. (Coleção Agenda brasileira).

GONZALEZ, L. Por um feminismo Afro-latino-americano. In: CIRCUITO PALMARINO. Caderno de Formação Política no Círculo Palmarino: AfroLatinoAmérica, São Paulo: Círculo Palmarino, 2011. n. 1, p. 12-20. Disponível em: https://edisciplinas.usp.br/ pluginfile.php/375002/mod_resource/content/0/caderno-deforma\%C3\%A7\%C3\%A3o-do-CP_1.pdf. Acesso em: 3 set. 2019.

LUSA. 'Rapper' angolana Eva Rap Diva entra hoje no mercado discográfico português com 'Eva'. RTP Notícias: Cultura, [Portugal], 1 jun. 2018. Disponível em: https://www.rtp.pt/noticias/cultura/rapperangolana-eva-rap-diva-entra-hoje-no-mercado-discografico-portuguescom-eva_n1079261. Acesso em: 10 jan. 2020. 
LUTE como uma menina! Produção: Beatriz Alonso; Flávio Colombini. São Paulo: Produtora independente. [S. l.: s. n.], 2016. 1 vídeo (76 min). Disponível em: https://www.youtube.com/watch?v=8OCUMGHm2oA. Acesso em: 3 jan. 2020.

MAMA, A. What does it mean to do feminist research in African contexts? Feminist Review: conference proceedings, [London], 1 set. 2011. p. 4-20. Disponível em: www.feminist- review.com . Acesso em: 20 dez. 2019.

MBEMBE, A. Sair da grande noite: ensaio sobre a África descolonizada. Tradução: Fábio Ribeiro. Petrópolis: Vozes, 2019. (Coleção África e os Africanos).

MENESES, M. P. Uma perspectiva cosmopolita sobre os estudos africanos: a lembrança e a marca de Aquino de Bragança. In: SILVA, T. C. e; COELHO, J. P. B.; SOUTO, A. N. de. (org.). Como fazer Ciências Sociais e Humanas em África: questões metodológicas, epistemológicas, teóricas e práticas. Dacar: CLACSO, 2012. p. 85-108. (Textos do Colóquio em Homenagem a Aquino de Bragança).

ORLANDI, E. P. Eu, tu, ele: discurso e real da história. 2.

ed. Campinas: Pontes, 2017.

ORLANDI, E. P. Análise de discurso: princípios e procedimentos. 12. ed. Campinas: Pontes, 2015.

ORLANDI, E. P. Discurso e texto: formulação e circulação de sentidos. 4. ed. Campinas: Pontes, 2012.

OYĚWÙMÍ, O. La invención de las mujeres: una perspectiva africana sobre los discursos occidentales del género. Tradução: Alejandro Montelongo González. Bogotá: La Frontera, 2017.

PETRUCCELLI, J. L.; SABOIA, A. L. Características étnico-raciais da população: classificações e identidades. Rio de Janeiro: IBGE, 2013. (Estudos e Análises: informação demográfica socioeconômica, n. 2). Disponível em: https://biblioteca.ibge.gov.br/visualizacao/livros/ liv63405.pdf. Acesso em: 30 abr. 2021.

POETISAS no topo. [S. 1.: s. n.], 2017. 1 vídeo (11 min). Disponível em: https://www.youtube.com/watch?time_continue = 264Eamp; $\mathrm{v}=$ oZYIIP PLfjY\&amp;feature = emb_title. Acesso em: 2 jan. 2020.

PÊCHEUX, M. Análise de discurso. Tradução: Eni P. Orlandi. 4. ed. Campinas: Pontes, 2015.

RATTS, A. Eu sou atlântica: sobre a trajetória de vida de Beatriz Nascimento. São Paulo: Instituto Kuanza; Imprensa Oficial, 2006.

SCHMIDT, S. P. Mulheres, negritude e a construção de uma modernidade transnacional. Revista. Estudos. Feministas., Florianópolis, v. 27, n. 1, p. 58957, 2019. Disponível em: https://www.scielo.br/j/ ref/a/DrfYZXrbXXKLP5VwyBhz7Hg/?format = pdfEamp;lang = pt. Acesso em: 5 jan. 2020. 
UNITED NATIONS. Res. 54/134, de 7 de fevereiro de 2000. Institui o Dia Internacional da Eliminação da Violência contra Mulheres. Disponível em: https://undocs.org/A/RES/54/134 . Acesso em: 12 fev. 2020.

WOLFF, C. S.; SCHMIDT, S. P.; GASPARETTO, V. F. Feminismos ao Sul: África e América Latina. Tópicos Especiais em Assuntos Interdisciplinares: programa da disciplina (em construção). Programa de Pós-Graduação Interdisciplinar em Ciências Humanas, Universidade Federal de Santa Catarina. Florianópolis: UFSC, 2019. Disponível em: https://dich.paginas.ufsc.br/files/2019/07/DISCIPLINA-FEMINISMOSAO-SUL.pdf Acesso em: 20 jul. 2019.

Submetido em: $14 / 06 / 2020$

Aceito em: 30/06/2020 